\title{
Primary Bone Lymphoma: A Retrospective Analysis of 22 Patients Treated in a Single Tertiary Center
}

\author{
Alexios Matikas ${ }^{a} \quad$ Alexandros Briasoulis $^{b} \quad$ Ifigeneia Tzannou $^{a}$ \\ Dimitra Oikonomopoulou ${ }^{a}$ Maria Bakiri $^{a}$ Themis Karmiris ${ }^{a}$ Nikolaos Harhalakis ${ }^{a}$ \\ aLymphoma, Hematology and Bone Marrow Transplant Department, Evangelismos General Hospital, Athens, Greece;

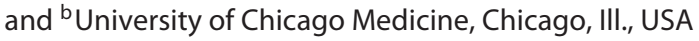

\section{Key Words}

Primary bone lymphoma $\cdot$ DLBCL $\cdot$ Chemotherapy ·

Rituximab

\section{Abstract}

Background: Primary bone lymphoma is a rare disease, representing less than $5 \%$ of all extra-nodal non-Hodgkin lymphomas. Materials and Methods: We retrospectively searched the database of the lymphoma unit, Hematology/ Lymphoma Department, Athens General Hospital 'Evangelismos' for primary bone lymphoma patients. Demographic and clinicopathologic data were collected and overall survival was analyzed. A log-rank test was used in a univariate analysis to identify factors affecting overall survival. $\boldsymbol{R e}$ sults: We identified 24 and analyzed data from 22 patients. 12 were male (54.5\%) and 10 female (45.4\%) and their median age was 55 years (range: 19-83). Most patients had localized disease at the time of diagnosis $(n=19,86.3 \%)$, the most common site was the spine $(n=11,50 \%)$ and the most common histology was diffuse large B-cell lymphoma. 21 patients received chemotherapy as initial therapy and 16 received combined chemoradiation. $81.8 \%$ of the patients $(n=$
18) achieved complete remission. 5-year survival rate was $86.3 \%$ and overall survival was found to be affected by the patients' initial response to treatment. Conclusions: Primary bone lymphoma is usually associated with a good prognosis. Prospective studies are needed in order to clarify the effect of immunochemotherapy in overall survival.

Copyright @ 2013 S. Karger AG, Basel

\section{Introduction}

Primary bone lymphoma (PBL) was recognized as a distinct entity for the first time in 1939 by Parker and Jackson [1]. The definition of PBL varies depending on the author; some include only patients with Ann Arbor stage I and II disease [2] and others also include stage IV patients [3]. PBL is a rare malignancy, accounting for 3\% of all primary malignant bone tumors in adults [4], 2\% of all lymphomas [5] and less than 5\% of all extra-nodal non-Hodgkin lymphomas (NHL) [6].

In most series, PBL is usually diagnosed between the ages $50-70$ and there is a male predominance. The most common histologic subtype is diffuse large B-cell lym-

\section{KARGER}

E-Mail karger@karger.com

www.karger.com/aha
(C) 2013 S. Karger AG, Basel

0001-5792/13/1304-0291\$38.00/0
Dr. Alexios Matikas, MD, MSc

24 Karvela Street

Agia Paraskevi

GR-15342 Athens (Greece)

E-Mail almatikas@gmail.com 
phoma (DLBCL); other rarer histologies have been consistently reported. Over the years, the treatment of PBL has evolved; from monotherapy with radiotherapy to combination chemotherapy or combined modality therapy and more recently to immunochemotherapy with the addition of the anti-CD20 monoclonal antibody rituximab. The 5-year overall survival has also improved along with the optimization of treatment strategies [7].

In the present study we aim to examine the clinicopathologic characteristics of all the cases of PBL that were treated at our institution during the past two decades, determine the outcome and assess whether the newer immunochemotherapy regimens affect the prognosis. We also briefly review the available literature.

\section{Patients and Methods}

\section{Definition of PBL}

WHO classifies PBL into four groups [8]; Group A: lymphoma involving a single bone site with or without regional lymph node involvement. Group B: lymphoma involving multiple bones but with no evidence of other disease sites. Group C: lymphoma involving a bone site at the presence of disseminated lymph node or visceral disease. Group D: lymphoma involving any part of the body, diagnosed by bone biopsy performed to rule out possible involvement. In our search we included patients belonging to groups $\mathrm{A}$ and $\mathrm{B}$.

\section{Patients}

We retrospectively searched the electronic records of the Lymphoma Unit, Hematology Lymphoma and Bone Marrow Transplant Department, 'Evangelismos' Athens General Hospital for patients who had received a diagnosis of primary bone lymphoma during the period 1992-2012. We identified 24 patients and collected data from 22. 2 were excluded from our analysis, 1 because the patient transferred his treatment to another hospital and another because of incomplete data. In all the cases there was pathological confirmation of the diagnosis. We collected and analyzed data regarding the patients' age, sex, site of disease, presenting symptoms, stage, histologic subtype, International Prognostic Index (IPI), first line treatment, response to treatment and overall survival.

\section{Staging and Response Assessment}

Staging was performed according to the Ann Arbor system. Patients with disease involving a single bone site were categorized as stage IE (WHO Group A). In case of regional lymph node involvement, they were categorized as stage IIE. Finally, stage IVE included patients with multiple bone involvement without evidence of distant nodal or visceral disease (WHO Group B). Stage IIIE patients, defined as those with distant nodal disease were excluded from the definition of PBL.

Assessment of response to treatment was defined according to the International Workshop Criteria (IWRC) [9]. Complete response (CR) was defined as disappearance of all detectable clinical and radiographic evidence of disease, excluding abnormalities attributed to bone remodeling. Partial response (PR) was defined as a $\geq 50 \%$ reduction of all measurable tumors. Progressive disease (PD) was defined as a $\geq 50 \%$ in the size of previously involved sites or the appearance of new lesions despite therapy. Finally, stable disease (SD) was defined as a response lesser than PR but not fulfilling the PD criteria.

Staging and response assessment investigations included complete blood count, blood chemistry including $\mathrm{LDH}$, bone marrow biopsy and imaging studies: magnetic resonance imaging (MRI) and/or computed tomography (CT) in all the patients; gallium scans in most and FDG-PET scans (Positron Emission Tomography) in the most recent cases after 2007, when the technique became available at our institution.

For comparative purposes, patients were divided in two groups, according to the chemotherapy regimen they received. In the first group there were the patients treated in the pre-rituximab era that had received with either CHOP-like (cyclophosphamide, doxorubicin, vincristine and prednisolone) or third generation regimens such as ProMACE Cyta-BOM (cyclophosphamide, doxorubicin, etoposide, bleomycin, vincristine, methotrexate and prednisolone). In the second group there were the patients that had been treated with R-CHOP-like (rituximab + CHOP) immunochemotherapy regimens.

\section{Statistical Analysis}

All statistical analyses were performed with SPSS (version 19.0; SPSS, Chicago, Ill., USA). All variables were tested for normal distribution of the data. The analyses were performed on an intention-to-treat and on-treatment basis. Normally distributed data were expressed as means \pm SD. For categorical variables, the $\chi^{2}$ or Fisher exact test, were used to compare the distributions of the groups. Nonparametric tests were used for between-group comparisons of continuous variables. Non-normally distributed data were presented as the median with the interquartile range. The Kaplan-Meier method was used to estimate the survival distributions. The log-rank test was used to compare the survival distributions. All significance tests were 2 tailed and conducted at the 5\% significance level.

\section{Results}

\section{Patient Characteristics}

The demographic and clinical characteristics of the patients are shown on table 1 . The median age was 55 years (range: $19-83$ years), with a 1.2:1 male to female ratio. 14 reported pain as one of their initial symptoms, 2 presented with fractures, 2 because of skin ulcers, 3 because of a palpable mass and only one patient reported $\mathrm{B}$ symptoms (fever, sweats, weight loss) as part of his initial symptoms.

The most common site of disease was the spine $(\mathrm{n}=$ $11,50 \%)$ followed by the extremities $(\mathrm{n}=7,31.8 \%)$ and the jaw $(n=4,18.1 \%)$. Most patients presented with Ann Arbor stage IE disease $(n=16,72.7 \%)$ compared to stage 
IIE $(\mathrm{n}=3,13.6 \%)$ and stage IV disease $(\mathrm{n}=3,13.6 \%)$. Most patients had a low IPI score (0-1: 63.6\%), indicating a good prognosis.

DLBCL was the most common histopathological subtype ( $\mathrm{n}=18,81.8 \%)$, the majority being of the Germinal center-like type. Other subtypes included a case of lymphoplasmacytic lymphoma (LPC), one T-cell lymphoma, one MALT lymphoma and a NHL not otherwise specified (NOS) because the patient had received radiotherapy before a biopsy was performed, due to spinal cord compression.

\section{Initial Treatment, Response and Survival}

Out of the 22 patients, 21 underwent chemotherapy and one patient was treated with radiotherapy alone. The majority of the chemotherapy-treated patients received $\mathrm{CHOP}$ or a variation (9 patients). 2 patients received the ProMACE Cyta-BOM regimen and 10 patients were treated with $\mathrm{R}-\mathrm{CHOP}$ or R-mini-CHOP (R-CHOP with half the doxorubicin dose). Patients received a mean of 5.71 chemotherapy cycles (range: $4-7$ ). 8 patients were treated with additional intrathecal methotrexate for CNS prophylaxis (range: 2-7 infusions). 17 patients were treated with radiotherapy; one as a monotherapy and 16 as part of a combined modality therapy. The median dose received was $37 \mathrm{~Gy}$ (range: 30-50 Gy).

According to IWRC criteria, $18 / 22$ patients (81.8\%) attained a complete response, $1 / 22(4.5 \%)$ a partial response, 1 patient had stable disease (4.5\%) and finally 2 patients progressed during first line treatment (9\%). Among the 19 responders one relapsed in the CNS and 4 had a systematic relapse.

Among the 6 cases with PBL who were deceased at the time of data extraction and analysis the median time to death after the diagnosis of PBL was 66.5 months (mean 86.8 , range $4-180$ months) (fig. 1). In that subgroup of patients with PBL causes of death were all lymphoma related. Among the 16 cases alive at the last follow-up visit, the median follow-up duration was 52 months (mean 55.46, range 9-136 months). The overall 1-, 5- and 10year survival rates of the 22 cases were $95.5,86.3,81.8 \%$, respectively. We compared the survival rate of patients following different treatments. Univariate analysis revealed that the overall survival rate was not significantly different between patients treated with R-CHOP and those treated with older chemotherapy regimens $\left(\chi^{2}\right.$ $0.291, \mathrm{p}=0.589$; fig. 2 ). We also sought to identify parameters that affected overall survival. Univariate analysis revealed that patients aged less than 50 years old had a better survival than those aged over 50 years old, a difference
Table 1. Patient demographic and clinical characteristics

\begin{tabular}{|c|c|}
\hline Characteristic & $\mathrm{n}(\%)$ \\
\hline \multicolumn{2}{|l|}{ Sex } \\
\hline Male & $12(54.5 \%)$ \\
\hline Female & $10(45.4 \%)$ \\
\hline \multicolumn{2}{|l|}{ Age } \\
\hline$<50$ & $7(31.8 \%)$ \\
\hline$>50$ & $15(68.1 \%)$ \\
\hline \multicolumn{2}{|l|}{ Stage } \\
\hline IE & $16(72.7 \%)$ \\
\hline IIE & $3(13.6 \%)$ \\
\hline IV & $3(13.6 \%)$ \\
\hline \multicolumn{2}{|l|}{ IPI } \\
\hline $0-1$ & $14(63.6 \%)$ \\
\hline$\geq 2$ & $4(18.1 \%)$ \\
\hline Not defined & $4(18.1 \%)$ \\
\hline \multicolumn{2}{|l|}{ Sites } \\
\hline Spine & $11(50 \%)$ \\
\hline Jaw & $4(18.1 \%)$ \\
\hline Extremities & $7(31.8 \%)$ \\
\hline \multicolumn{2}{|l|}{ Histology } \\
\hline DLBCL & $18(81.8 \%)$ \\
\hline Other & $4(18.1 \%)$ \\
\hline \multicolumn{2}{|l|}{ Initial treatment } \\
\hline CHOP & $9(40.9 \%)$ \\
\hline $\mathrm{R}-\mathrm{CHOP}$ & $10(45.4 \%)$ \\
\hline ProMACE Cyta-BOM & $2(9 \%)$ \\
\hline RT alone & $1(4.5 \%)$ \\
\hline \multicolumn{2}{|l|}{ IT-MTX } \\
\hline Yes & $8(36.3 \%)$ \\
\hline No & $14(63.6 \%)$ \\
\hline \multicolumn{2}{|l|}{ RT } \\
\hline Yes & $17(77.2 \%)$ \\
\hline No & $5(22.7 \%)$ \\
\hline \multicolumn{2}{|l|}{ Response } \\
\hline CR & $18(81.8 \%)$ \\
\hline PR & $1(4.5 \%)$ \\
\hline SD & $1(4.5 \%)$ \\
\hline $\mathrm{PD}$ & $2(9 \%)$ \\
\hline
\end{tabular}

IPI = International prognostic index DLBCL = diffuse large Bcell lymphoma; $\mathrm{CHOP}=$ cyclophosphamide, doxorubicin, vincristine, prednisolone; $\mathrm{R}-\mathrm{CHOP}=$ rituximab + CHOP; ProMACE Cyta-BOM = cyclophosphamide, doxorubicin, etoposide, bleomycin, vincristine, methotrexate, prednisolone; $\mathrm{RT}=$ radiotherapy; ITMTX = intrathecal methotrexate; $\mathrm{CR}=$ complete response; $\mathrm{PR}=$ partial response; $\mathrm{SD}=$ stable disease $; \mathrm{PD}=$ progressive disease .

that bordered but did not reach significance $(\mathrm{p}=0.097)$. Survival was affected by the response to initial treatment: patients attaining a complete or partial response had a significantly longer overall survival $(\mathrm{p}<0.0001)$. Stage, gender, histology, IPI score and use of radiotherapy were not found to be prognostic indicators in our series. 


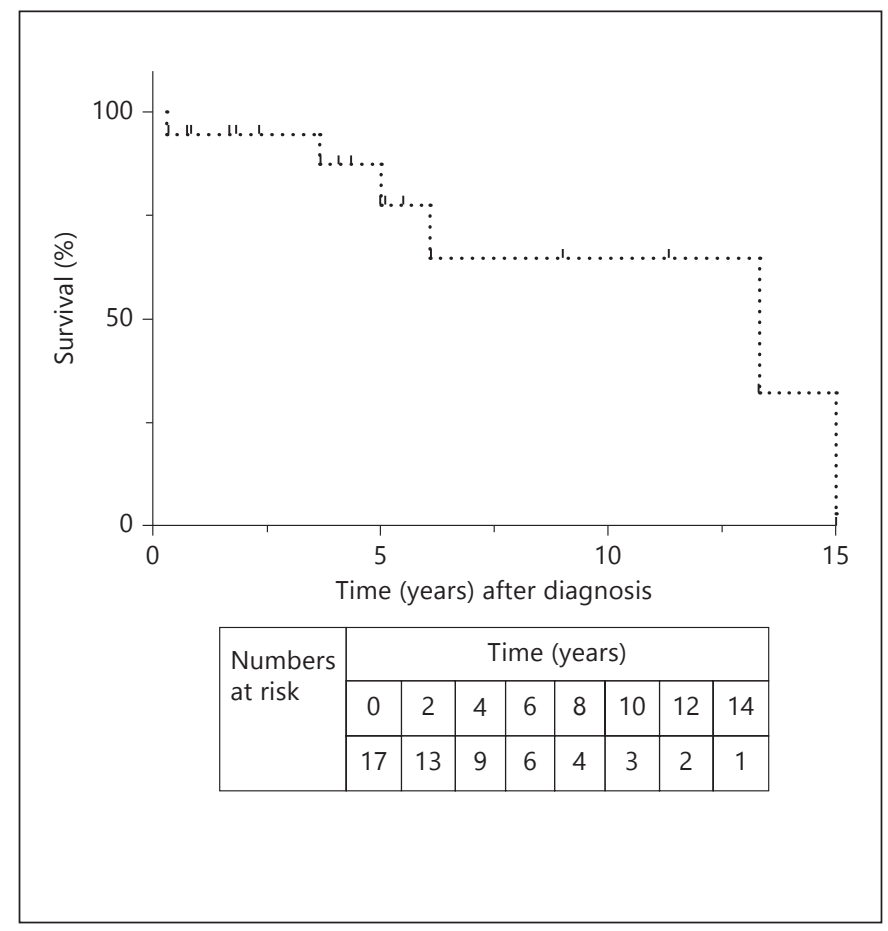

Fig. 1. Overall survival of patients with primary bone lymphoma.

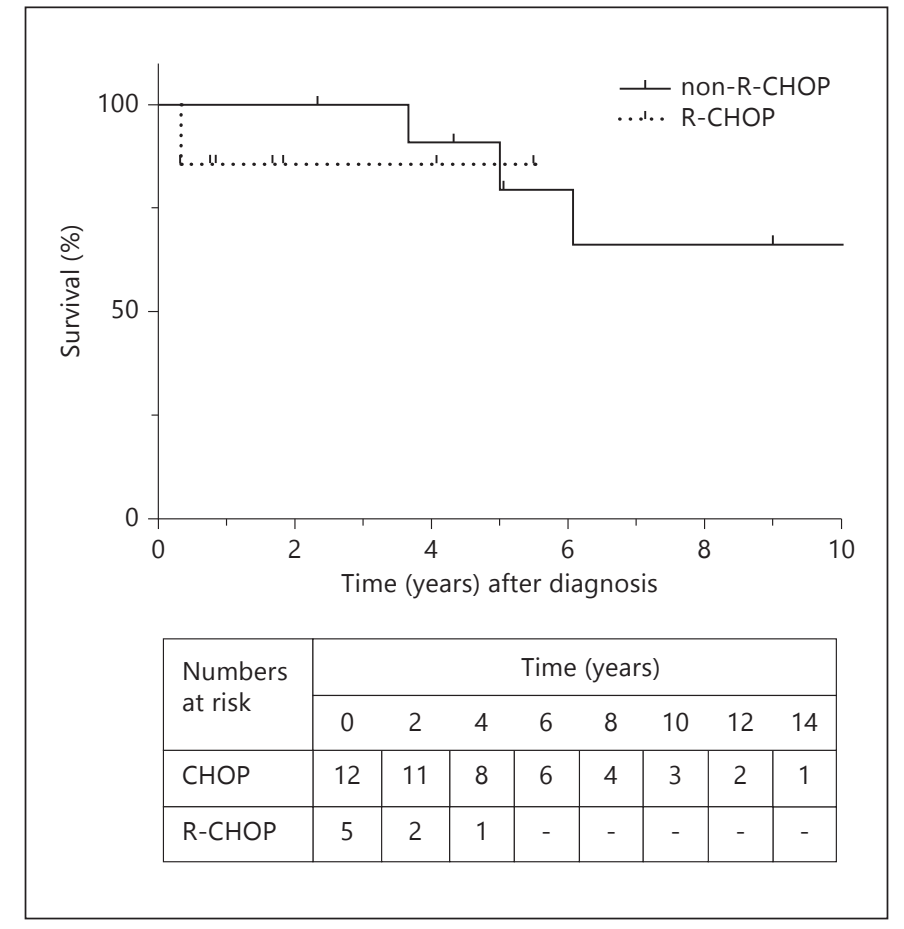

Fig. 2. 10-year survival rates of patients treated with immunochemotherapy and patients treated with older chemotherapy regimens.

Table 2. Summary of all the PBL series of the past decade

\begin{tabular}{lclclc}
\hline Study & $\mathrm{n}$ & Median age & Stage I-II & ORR & OS, \% years \\
\hline Zinzani 2003 [16] & 52 & 58 & 79 & 90 & $68(9)$ \\
Stein 2003 [19] & 19 & 54 & 58 & 89 & NA \\
Lewis 2003 [20] & 28 & 45 & 71 & NA & $58(5)$ \\
de Leval 2003 [21] & 29 & 44 & 62 & NA & $74(5)$ \\
Barbieri 2004 [22] & 77 & 42 & 100 & 95 & 88 \\
Beal 2006 [3] & 82 & 48 & 81 & NA & $88(5)$ \\
Horsman 2006 [23] & 37 & 55 & 100 & 57 & 64 \\
Maruyama 2007 [13] & 28 & 47 & 32 & 88 & $84(3)$ \\
Ramadan 2007 [17]* & 131 & 63 & 46 & 84 & $62(5)$ \\
Jawad 2010 [7] & 1,500 & NA & 69.1 & NA & $58(5)$ \\
Alencar 2010 [24] & 53 & 52 & 77 & 85 & $83(4)$ \\
Pellegrini 2011 [25] & 21 & 34 & NA & 95 & $95(8)$ \\
Nasiri 2011 [26] & 28 & 41 & 75 & NA & 54 months \\
Cai 2012 [27] & 116 & 50 & 100 & 91 & $76(5)$ \\
Kim 2012 [28] & 33 & 40 & 39 & 88 & 166 months \\
\hline
\end{tabular}

ORR = Overall response; OS = overall survival.

* Response rate and survival only for patients with DLBCL. 


\section{Discussion}

Primary bone lymphoma is a rare disease and thus, the design and completion of prospective studies is challenging, meaning that experience in the literature comes from small retrospective case series.

In our series, DLBCL was the most common histopathologic subtype in accordance to other series [10]. However, almost any lymphoma histology has been reported causing primary bone disease, including low grade histologies, anaplastic lymphoma [11] and Burkitt lymphoma [12]. Interestingly, the sites of occurrence differ among the various studies: in two series of Japanese patients, PBL most commonly involved the pelvis, $[13,14]$ in others the most common sites of disease were the long bones, $[15,16]$ another study of 131 patients of the British Columbia Cancer Agency reported equal frequency between axial and extremity involvement [17] and finally the SEER database study reported a predominance of axial involvement among 1,500 PBL patients [7], a finding our study shares.

Radiotherapy was first used in the treatment of PBL 40 years ago, achieving for the first time disease control [18]. Combination chemotherapy results in durable responses but no prospective randomized studies have been performed to optimize treatment strategies. In a retrospective series of 52 consecutive patients, $85 \%$ of the patients that received chemotherapy with or without radiotherapy attained a complete response, compared to 64\% of those that were treated with radiotherapy alone [16]. The effect of combined modality treatment (chemoradiotherapy) was positive in another series of 82 patients: 5 -year survival rate was $95 \%$ compared to $78 \%$ of the single modality approach $(\mathrm{p}=0.013)$ [3]. However, the study of the British Columbia Cancer Agency reported conflict- ing results [17]. More recently, the introduction of the anti-CD20 monoclonal antibody rituximab has transformed the treatment of non-Hodgkin lymphomas. The large number of small retrospective studies that report conflicting results hinders our ability to draw conclusions regarding the effect of rituximab in the overall survival of PBL patients $[17,24,25,28]$.

The prognosis of PBL is relatively good and on a par with same-stage systemic DLBCL. In our series, the 5-year survival rate was $86.3 \%$ and we found that it was affected by the patients' age and response to first line treatment. The reported 5-year survival rates vary greatly, from $60 \%$ for the patients diagnosed after 1996 in the SEER database study up to $95.2 \%$ in a series published by Pellegrini et al. $[7,25]$. Moreover, various studies report different prognostic factors, such as age [7], sex [3], stage [17], lactate dehydrogenase levels [3], histologic subtype [13] and IPI [17], even though the Memorial Sloan-Kettering Cancer Center study concluded that IPI status did not affect the prognosis [3]. Table 2 summarizes all the PBL series that were published in the literature during the past 10 years when use of immunochemotherapy became widespread in the treatment of non-Hodgkin lymphomas.

In conclusion, we retrospectively analyzed data from 22 primary bone lymphoma patients treated at our institution during the past 20 years and we briefly reviewed the available literature. However, carefully designed prospective studies are needed that will help clarify many aspects of the disease.

\section{Acknowledgements}

The authors would like to express their gratitude to Dr Nikos Papageorgiou for his valuable contributions throughout the preparation of this manuscript.

\section{References}

1 Parker F, Jackson H: Primary reticulum cell sarcoma of bone. Surg Gynecol Obstet 1939; 68:45-53.

2 Fidias P, Spiro I, Sobczak ML, Nielsen GP, Ruffolo EF, Mankin H, Suit HD, Harmon DC: Long-term results of combined modality therapy in primary bone lymphomas. Int J Radiat Oncol Biol Phys 1999;45:12131218.

3 Beal K, Allen L, Yahalom J: Primary bone lymphoma: treatment results and prognostic factors with long-term follow-up of $82 \mathrm{pa}$ tients. Cancer 2006;106:2652-2656.
-4 Limb D, Dreghorn C, Murphy JK, Mannion R: Primary lymphoma of bone. Int Orthop 1994; 18:180-183.

5 Dubey P, Ha CS, Besa PC, Fuller L, Cabanillas F, Murray J, Hess MA, Cox JD: Localized primary malignant lymphoma of bone. Int J Radiat Oncol Biol Phys 1997;37:1087-1093.

-6 Freeman C, Berg JW, Cutler SJ: Occurrence and prognosis of extranodal lymphomas. Cancer 1972;29:252.

7 Jawad MU, Schneiderbauer MM, Min ES, Cheung MC, Koniaris LG, Scully SP: Primary Lymphoma of Bone in Adult Patients. Cancer 2010;116:871-879.
8 Swerdlow SH, Steven H: WHO Classification of Tumours of Haematopoietic and Lymphoid Tissues (ed 4th). Lyon, France: IARC Press; 2008.

9 Cheson BD, Horning SJ, Coiffier B, Shipp MA, Fisher RI, Connors JM, Lister TA, Vose J, Grillo-López A, Hagenbeek A, Cabanillas F, Klippensten D, Hiddemann W, Castellino R, Harris NL, Armitage JO, Carter W, Hoppe R, Canellos GP: Report of an international workshop to standardize response criteria for non-Hodgkin's lymphomas. NCI Sponsored International Working Group. J Clin Oncol 1999;17:1244. 
10 Mikhaeel NG: Primary Bone Lymphoma. Clin Oncol 2012;24:366-370.

11 Wang J, Kim D, Goldberg M: Anaplastic Large Cell Ki-1 Lymphoma: Primary Bone Presentation in an Elderly Man. Acta Haematol 1996;96:45-49.

\12 Tanimura A, Adachi Y, Tanda M, Yuasa H, Ishii Y, Katou Y: Primary Peripheral B Cell Lymphoma, Burkitt-Like, of the Cranial Vault. Acta Haematol 2005;113:258-261.

13 Maruyama D, Watanabe T, Beppu Y, Kobayashi Y, Kim SW, Tanimoto K, Makimoto A, Kagami Y, Terauchi T, Matsuno Y, Tobinai K: Primary Bone Lymphoma: A New and Detailed Characterization of 28 Patients in a Single-Institution Study. Jpn J Clin Oncol 2007; 37:216-223.

14 Ueda T, Aozasa K, Ohsawa M, Yoshikawa H, Uchida A, Ono K, Matsumoto K: Malignant lymphomas of bone in Japan. Cancer 1989;64: 2387-2392.

15 Heyning FH, Hogendoorn PC, Kramer MH, Hermans J, Kluin-Nelemans JC, Noordijk EM, Kluin PM: Primary non-Hodgkin's lymphoma of bone: a clinicopathological investigation of 60 cases. Leukemia 1999;13:20942098.

16 Zinzani PL, Carrillo G, Ascani S, Barbieri E, Tani M, Paulli M, Stefoni V, Sabattini E, Alinari L, Binazzi R, Tura S, Baccarani M, Pileri SA: Primary Bone Lymphoma: experience with 52 patients. Haematologica 2003;88:280-285.
7 Ramadan KM, Shenkier T, Sehn LH, Gascoyne RD, Connors JM: A clinicopathological retrospective study of 131 patients with primary bone lymphoma: a population-based study of successively treated cohorts from the British Columbia Cancer Agency. Ann of Oncol 2007;18:129-135.

18 Dosoretz DE, Murphy GF, Raymond AK, Doppke KP, Schiller AL, Wang CC, Suit HD: Radiation therapy for primary lymphoma of bone. Cancer 1983;51:44-46.

19 Stein ME, Kuten A, Gez E, Rosenblatt KE, Drumea K, Ben-Shachar M, Zidan J, Haim N, Epelbaum R: Primary lymphoma of bone - a retrospective study. Oncology 2003;64:322327.

20 Lewis VO, Primus G, Anastasi J, Doherty D, Montag AG, Peabody TD, Simon MA: Oncologic outcomes of primary lymphoma of bone in adults. Clin Orthop Relat Res 2003;415:9097.

21 de Leval L, Braaten KM, Ancukiewicz M, Kiggundu E, Delaney T, Mankin HJ, Harris NL: Diffuse large B-cell lymphoma of bone. An analysis of differentiation-associated antigens with clinical correlation. Am J Surg Pathol 2003;27:1269-1277.

22 Barbieri E, Cammelli S, Mauro F, Perini F, Cazzola A, Neri S, Bunkheila F, Ferrari S, Brandoli V, Zinzani P, Mercuri M, Bacci G: Primary non-Hodgkin's lymphoma of the bone: treatment and analysis of prognostic factors for stage I and stage II. Int J Radiat Oncol Biol Phys 2004;59:760-764.
23 Horsman JM, Thomas J, Hough R, Hancock BW: Primary bone lymphoma: a retrospective analysis. Int J Oncol 2006;28:1571-1575.

24 Alencar A, Pitcher D, Byrne G, Lossos IS: Primary bone lymphoma - the University of Miami experience. Leuk Lymphoma 2010;51: 39-49.

25 Pellegrini C, Gandolfi L, Quirini F, Ruggieri P, Stefoni V, Derenzini E, Broccoli A, Argnani L, Pileri S, Mercuri M, Baccarani M, Zinzani PL: Primary bone lymphoma: evaluation of chemoimmunotherapy as front-line treatment in 21 patients. Clin Lymphoma Myeloma Leuk 2011;11:321-325.

26 Nasiri MR, Varshoee F, Mohtashami S, Raziee HR, Aledavood A, Ghafarzadeh K, Memar B, Vojdani S, Sarvizadeh M: Primary bone lymphoma: a clinicopathological retrospective study of 28 patients in a single institution. J Res Med Sci 2011;16:814-820.

27 Cai L, Stauder MC, Zhang YJ, Poortmans P, Li YX, Constantinou N, Thariat J, Kadish SP, Nguyen TD, Kirova YM, Ghadjar P, Weber DC, Bertran VT, Ozsahin M, Mirimanoff RO: Early-stage primary bone lymphoma: a retrospective, multicenter Rare Cancer Network (RCN) Study. Int J Radiat Oncol Biol Phys 2012;83:284-291.

28 Kim SY, Shin DY, Lee SS, Suh C, Kwak JY, Kim HG, Lee JH, Lee SI, Lee YR, Kang SH, Mun SK, Lee MJ, Lee HR, Yang SH, Kang HJ: Clinical characteristics and outcomes of primary bone lymphoma in Korea. Korean J Hematol 2012;47:213-218. 